\title{
The effect of aging on the repeated-dose liver micronucleus assay
}

\author{
Miyuki Shigano $^{1^{*}}$ (D), Hironao Takasawa ${ }^{1}$ and Shuichi Hamada ${ }^{2}$
}

\begin{abstract}
Background: The liver micronucleus (MN) assay is an effective and important in vivo test for detecting genotoxic compounds. In particular, the repeated-dose liver MN (RDLMN) assay which greatly facilitates incorporation of the liver MN assay into the general toxicity study has been developed. Usefulness of the RDLMN assay was appraised highly in the 7th International Workshops on Genotoxicity Testing (2017 in Tokyo) in that sufficient numbers and types of chemicals were studied and easy integration into the general toxicity study is preferred from the 3R's point of view. However, it was pointed out that it is necessary to evaluate the effect of age at the start of 4-week repeated administration, since there are limited data, where only those of rats of 6 week of age at the start of administration are available.

In this study, we conducted the 4-week RDLMN assay using rats of 6 and 8 weeks of age (at the start of administration) to investigate the effect of age on the liver MN inducibility. Clofibrate, a weak inducer of liver MN, was used in this study to detect the slight difference in the liver MN induction.

Results: The liver MN induced by clofibrate was detected in both rats of 6 and 8 weeks of age at the start of administration. However, the liver MN induction was lower in rats of 8 weeks of age compared to rats of 6 weeks of age at the start of administration.

Conclusion: These results suggest that the liver MN inducibility decreases with age. Therefore, we recommend the use of rats of 6 weeks of age at start of administration to reliably detect the liver MN induction in the RDLMN assay.
\end{abstract}

Keywords: Liver micronucleus assay, Collagenase, Hepatocyte, Repeated-dose liver micronucleus assay, Clofibrate

\section{Introduction}

The liver MN assay is useful to evaluate the genotoxic potential to induce chromosome aberration in the liver. Especially, the repeated-dose liver MN (RDLMN) assay has been developed well in the Mammalian Mutagenicity Study Group (MMS) in the Japanese Environmental Mutagen Society (JEMS) because it could be incorporated into the general toxicity study. In the Collaborative Study Group for the Micronucleus Test (CSGMT) of JEMS/MMS, 22 carcinogens were evaluated in the RDLMN assay, in which hepatocarcinogens showed a

\footnotetext{
* Correspondence: shigano.miyuki@ma.medience.co.jp

${ }^{1}$ Safety Assessment Department, Kashima Laboratories, LSIM Safety Institute Corporation, 14-1 Sunayama, Kamisu-shi, Ibaraki 314-0255, Japan

Full list of author information is available at the end of the article
}

positive response in the liver $[1,2]$. In additional tests, aneugens showed a positive response in the liver and non-carcinogens showed a negative response in the RDLMN assay. These results were reported in the 7th International Workshop on Genotoxicity Testing (IWGT, 2017 in Tokyo), and the working group agreed that the RDLMN assay is sufficiently validated for an OECD guideline in terms of numbers and types of chemicals studied [3]. However, some issues were pointed out; it is necessary to evaluate the effect of age (6 weeks versus older) at the start of administration. This is because some countries, especially Western countries, conduct the general toxicology study using rats older than 6 weeks at start of administration, whereas the CSGMT

(c) The Author(s). 2021 Open Access This article is licensed under a Creative Commons Attribution 4.0 International License, which permits use, sharing, adaptation, distribution and reproduction in any medium or format, as long as you give appropriate credit to the original author(s) and the source, provide a link to the Creative Commons licence, and indicate if changes were made. The images or other third party material in this article are included in the article's Creative Commons licence, unless indicated otherwise in a credit line to the material. If material is not included in the article's Creative Commons licence and your intended use is not permitted by statutory regulation or exceeds the permitted use, you will need to obtain permission directly from the copyright holder. To view a copy of this licence, visit http://creativecommons.org/licenses/by/4.0/ The Creative Commons Public Domain Dedication waiver (http://creativecommons.org/publicdomain/zero/1.0/) applies to the data made available in this article, unless otherwise stated in a credit line to the data. 
described above used only rats of 6 weeks of age at the start of administration.

Clofibrate is an exogenous ligand of peroxisome proliferator-activated receptor alpha (PPAR $\alpha)$, and it is suggested that clofibrate generates reactive oxygen species through PPAR $\alpha$ and induces liver cancer in rats. Clofibrate showed a weak liver $\mathrm{MN}$ induction in the 2week and 4-week RDLMN assays using rats of 6 weeks of age at the start of administration [4].

We conducted the 4-week RDLMN assay using rats of 6 and 8 weeks of age at the start of administration to examine the effect of age on the results of the RDLMN assay. Clofibrate, a weak inducer of the liver MN, was used in this study to detect the slight difference in the liver $\mathrm{MN}$ induction.

\section{Materials and methods}

\section{Animals}

Male Crl:CD (SD) rats aged 5 and 7 weeks were purchased from Charles River Japan Inc. (Yokohama, Japan) and were aged 6 and 8 weeks at the start of administration. The animals were housed two to three per cage in an airconditioned room with a 12-h light/dark cycle and free access to food and drinking water. The experimental protocol was approved by the Institutional Animal Care and Use Committee prior to its implementation.

\section{Chemicals}

Clofibrate (CAS No. 637-07-0, >98.0\% purity) was purchased from Wako Pure Chemical Industries, Ltd. (Tokyo, Japan). Clofibrate was suspended in corn oil (Wako Pure Chemical Industries, Ltd.). The vehicle was used as the control substance.

\section{Dose levels and treatment schedules}

Clofibrate was administered orally to rats ( $n=5$ /group) at 0 (vehicle alone), $125 \mathrm{mg} / \mathrm{kg}$, and $500 \mathrm{mg} / \mathrm{kg}$ for 28 consecutive days. All dose volumes were set at $10 \mathrm{~mL} /$ $\mathrm{kg} /$ day. All animals were checked daily for clinical signs and weighed on Days 1, 8, 15, 22, and 29. The date of the first administration of the test chemical was regarded as Day 1.

\section{Liver micronucleus assay}

Twenty-four hours after the last administration, rats (10 and 12 weeks of age) were euthanized under thiopental anesthesia. Then, the liver were removed from each rat and the central part of lateral left lobe was used for the liver $\mathrm{MN}$ assay as previously reported [1, 2, 5]. Briefly, a small portion of the liver tissue (approximately 1 to $2 \mathrm{~g}$ around the central part of the lateral left lobe) was sliced at about $2 \mathrm{~mm}$ with a razor blade and washed well with physiological saline. The sliced liver was incubated in about $20 \mathrm{~mL}$ of a collagenase solution (containing
Collagenase Yakult: 40-50 U/mL Yakult Pharmaceutical Industry Co., Ltd., Tokyo, Japan, Lot No.: 121026-01) at $37^{\circ} \mathrm{C}$ for $1 \mathrm{~h}$ while being shaken at approximately 50 rpm. After the incubation, the liver tissues and the collagenase solution were mixed vigorously to isolate the hepatocytes (HEPs). The mixture was filtered through gauze and a cell strainer (pore size: $100 \mu \mathrm{m}$ ). The HEP suspension was centrifuged at $50 \times g$ for $2 \mathrm{~min}$ and the supernatant was discarded. About $20 \mathrm{~mL}$ of $10 \%$ phosphate buffered formalin was added to the pellet. The centrifugation was repeated and the supernatant was discarded. The pellet of the HEPs was mixed with $10 \%$ phosphate-buffered formalin to prepare an HEPsuspension. Just before microscopic observation, the prepared HEP-suspension was mixed and stained with the same volume of a staining solution containing acridine orange $(\mathrm{AO})$ at $500 \mu \mathrm{g} / \mathrm{mL}$ and 4',6-diamidino-2-phenylindole dihydrochloride (DAPI) at $10 \mu \mathrm{g} / \mathrm{mL}$ (AO-DAPI). The mixtures were dropped onto clean glass slides and spread with coverslips. The slide specimens were observed under a fluorescent microscope (BX51N-34-FL-1-D; Olympus Corporation, Tokyo, Japan) with a UV-excitation filter (wave length: 330-385 nm) and an emission filter (wave length: $420 \mathrm{~nm})$.

\section{Calculation of micronucleus incidences and mitotic indices, and statistics}

The incidence of micronucleated HEPs (MNHEPs) was calculated by counting 2000 HEPs for each animal. In addition, the number of mitotic phase cells in 2000 HEPs was counted to determine the mitotic index (MI). Differences in the incidence of MNHEPs between the clofibrate-treated and vehicle control groups were analyzed using the conditional binomial test of Kastenbaum and Bowman [6] for each age group. To evaluate the difference in sensitivity, the concentrations of clofibrate and MNHEP (\%) were fit to the regression line using the least squares regression (Microsoft Excel 2016, Microsoft Corporation). Body weights were using Bartlett's test for homogeneity of variance among groups. Since the variances were homogeneous in both the ages of treated animals, Dunnett's parametric test was applied. Significance was evaluated at the $5 \%$ or $1 \%$ level using a two-tailed test for increases or decreases relative to the vehicle control group for each age group.

\section{Results}

\section{Clinical sign and body weights}

In rats of 6 weeks of age at the start of administration, the body weights in the $500 \mathrm{mg} / \mathrm{kg}$ group were significantly lower than that in the control group on and after Day 8 (Fig. 1A). In the $500 \mathrm{mg} / \mathrm{kg}$ group, staggering gait and salivation were observed from Days 1 to 7 and from Days 13 to 28, respectively (data not shown). On the 

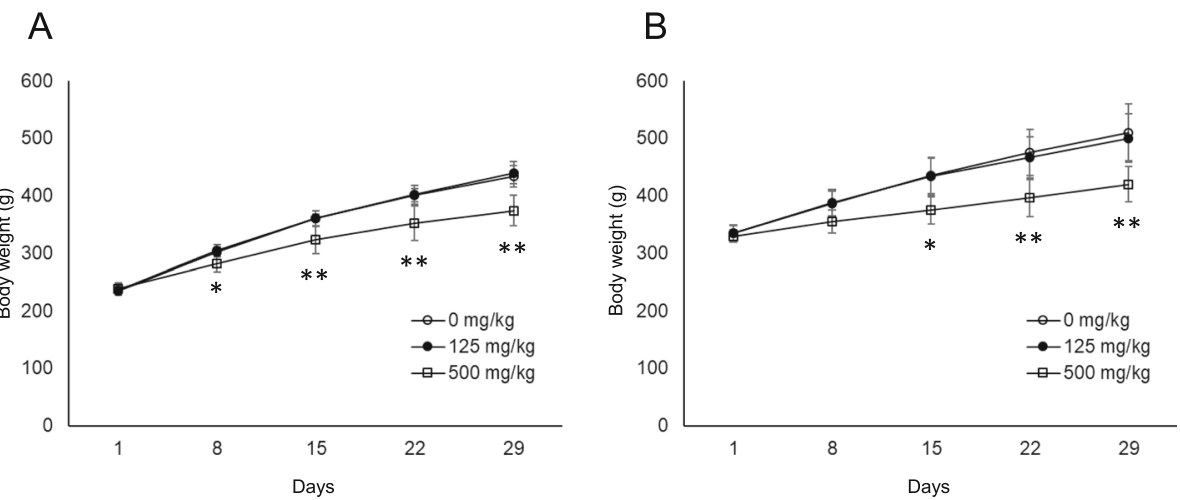

Fig. 1 Comparison of body weights of rats of 6 and 8 weeks of age at the start of administration using clofibrate. Body weights (g); Comparison between the vehicle group and clofibrate-treated group in rats of 6 weeks of age $(\mathbf{A})$ and rats of 8 weeks of age $(\mathbf{B})$ at the start of administration. Values are presented as the mean and SD. Differences in the body weights between the test and vehicle control groups were analyzed by the

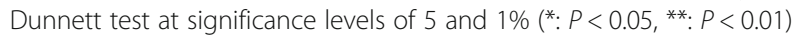

other hand, in rats of 8 weeks of age at the start of administration, the body weights in the $500 \mathrm{mg} / \mathrm{kg}$ group were significantly lower than that in the control group on and after Day 15 (Fig. 1B). In the $500 \mathrm{mg} / \mathrm{kg}$ group, staggering gait and salivation were observed from Days 1 to 4 and Days 15 to 28 , respectively (data not shown).

\section{Comparison of incidences of micronucleated hepatocytes and indices of $\mathrm{M}$-phase in hepatocytes}

In rats of 10 weeks of age at the end of administration ( 6 weeks of age at the start of administration), the incidences of MNHEPs in the 125 and $500 \mathrm{mg} / \mathrm{kg}$ groups were significantly higher than that in the control group (Fig. 2). The indices of $\mathrm{M}$ phase in hepatocytes ( $\mathrm{M}$ phase, \%) were $0.000 \pm 0.000 \%, 0.005 \pm 0.011 \%$, and $0.010 \pm 0.022 \%$ at 0,125 and $500 \mathrm{mg} / \mathrm{kg}$, respectively. On the other hand, in rats of 12 weeks of age at end of administration ( 8 weeks of age at the start of administration), the incidences of MNHEPs were significantly higher only in the $500 \mathrm{mg} / \mathrm{kg}$ group than that in the control group (Fig. 2). There were no $M$ phase hepatocytes ( $M$ phase: $0.000 \pm 0.000 \%$ in all groups). The sensitivity to clofibrate in rats of 12 weeks of age at the end of administration (slope: 0.0002) was lower than that in rats

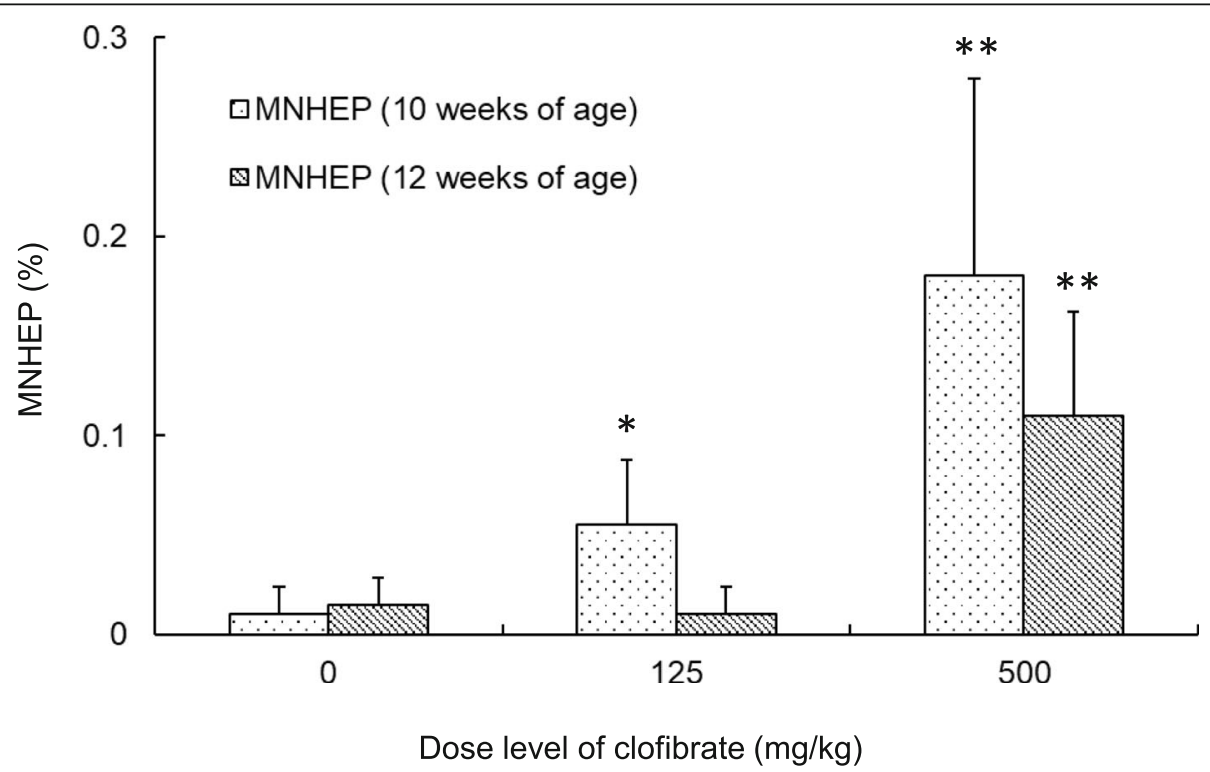

Fig. 2 Comparison of RDLMN assay results of rats of 10 and 12 weeks of age at the end of administration using clofibrate. Incidences of MNHEPs (\%); Comparison between the vehicle group and clofibrate-treated group in rats of 10 and 12 weeks of age at the end of administration. Differences in the incidences of MNHEPs between the test and vehicle control groups were analyzed by the Kastenbaum and Bowman test at significance levels of 5 and $1 \%\left({ }^{*}: P<0.05,{ }^{*}: P<0.01\right)$ 
of 10 weeks of age at the end of administration (slope: 0.0003, Fig. 3).

\section{Discussion}

At the 7th IWGT, it was pointed out that it would be necessary to evaluate the effect of age ( 6 weeks versus older) since most of the liver $\mathrm{MN}$ validation studies used rats of 6 weeks of age at the start of administration whereas rats of 8 weeks of age are used for the general toxicology study in many laboratories [3]. Micronuclei formation requires cell proliferation. The effect of age on the micronucleus assay has also been reported in the bone marrow MN assay, and are thought to be due to changes in cell proliferation ability with aging [7]. In the liver $\mathrm{MN}$ assay, $\mathrm{MN}$ induction has been evaluated using juvenile rats (4 weeks old) with active hepatocyte proliferation [8-11].

The repeated dose method enables MN induction in adult rats by utilizing accumulation of hepatocytes with micronuclei, but the effect of age needs to be examined. In this study, a 4-week RDLMN assay was conducted to evaluate the effect of age on the liver $\mathrm{MN}$ induction using rats of 6 and 8 weeks of age at the start of administration. To detect slight difference in liver $\mathrm{MN}$ induction, we selected clofibrate, a weak liver MN inducibility and dosed it to rats. As a result, liver MN induction was detected in both rats of 6 and 8 weeks of age at the start of administration. Although there were individual differences in MNHEP (\%) in rats of 6 weeks of age at the start of administration, it is considered that there are some differences in sensitivity due to age. The differences due to age in the liver $\mathrm{MN}$ induction are likely caused by mitotic activity. However, $M$ phase hepatocytes were rarely observed at specimen preparation (4 weeks after the start of administration) in rats of 10 and 12 weeks of age at the end of administration. It suggests that the differences in mitotic activity were due to the age of animals at the start of administration and cell division decreases with age. This implies that younger animals are more sensitive to liver MN induction as they showed a higher rate of hepatocyte proliferation, although the rates of replicative DNA synthesis were similar in rats aged from 5 to 8 weeks as previously reported [12]. Since MNHEPs were accumulated in the liver during 28-day administration, these can be detected if a chemical has some liver MN inducibility like clofibrate, but these may not be detected if a chemical has less inducibility in animals with less mitotic activity; i.e. rats of 8 weeks of age at the start of administration. Also, since clofibrate is metabolized by CYP, there are likely effects of age on CYP. Asaoka et al. [13] reported that the total CYP content was low in rats of postnatal day 4 , and increased with age. Although the toxicity assessment parameters other than clinical sign observation and body

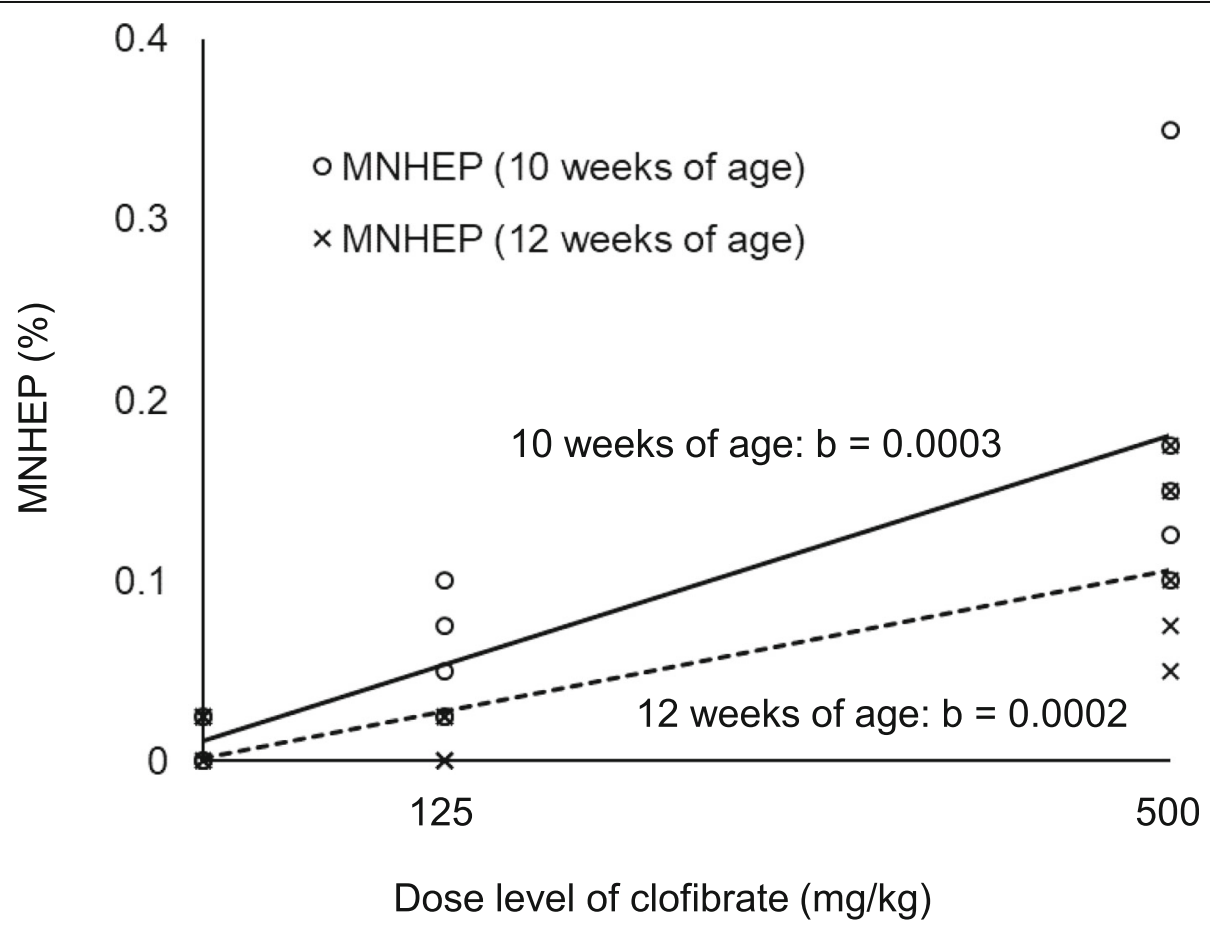

Fig. 3 Comparison of sensitivity of RDLMN assay of rats of 10 and 12 weeks of age at the end of administration using clofibrate. Individual values of the incidence of MNHEPs (\%) and the regression line (solid line: rats of 10 weeks of age at the end of administration, dotted line: rats of 12 weeks of age at the end of administration). The $b$ values are estimates of the slope 
weight measurement were not evaluated in this study, it is possible that differences in CYP expression or activity caused differences in toxicity, which lead to differences in MNHEP induction.

In conclusion, both rats of 6 and 8 weeks of age at the start of administration can be used for the RDMN assay, however, the sensitivity is considered to be higher in rats of 6 weeks of age. Further studies with several compounds may be necessary to determine usability of rats of 8 weeks of age at the start of administration in the RDLMN assay.

\section{Abbreviations \\ RDLMN assay: Repeated-dose liver micronucleus assay; CSGMT: The Collaborative Study Group for the Micronucleus Test; JEMS: The Japanese Environmental Mutagen Society; MMS: Mammalian Mutagenicity Study Group; MNHEP: Micronucleated hepatocyte; HEP: Hepatocyte}

\section{Acknowledgements}

The authors thank MMS/JEMS for their support, especially for statistical analysis by Dr. Takeiri. The authors are indebted to Mrs. K. Nakadate for her technical assistances and Mrs. K. Tamatsukuri for her critical review of the manuscript.

\section{Authors' contributions}

MS, HT, and SH conducted liver micronucleus assay and performed comprehensive evaluation. MS created table, fig and manuscript. All authors have read and approved the final manuscript.

\section{Funding}

Not applicable.

\section{Availability of data and materials}

All date generated or analyzed during this study are included in this published article.

\section{Declarations}

Ethics approval and consent to participate

The experimental protocol was approved by the Institutional Animal Care and Use Committee prior to its implementation.

\section{Consent for publication}

Not applicable.

\section{Competing interests}

The authors declare that they have no competing interests.

\section{Author details}

'Safety Assessment Department, Kashima Laboratories, LSIM Safety Institute Corporation, 14-1 Sunayama, Kamisu-shi, Ibaraki 314-0255, Japan. Bozo Research Center Inc, 1-3-11, Hanegi, Setagaya-ku, Tokyo 156-0042, Japan.

Received: 2 June 2021 Accepted: 29 August 2021

Published online: 09 September 2021

\section{References}

1. Hamada S, Ohyama W, Takashima R, Shimada K, Matsumoto K, Kawakami S, et al. Evaluation of the repeated-dose liver and gastrointestinal tract micronucleus assays with 22 chemicals using young adult rats: summary of the collaborative study by the collaborative study Group for the Micronucleus Test (CSGMT)/the Japanese environmental mutagen society (JEMS) - mammalian mutagenicity study group (MMS). Mutat Res. 2015;780781:2-17.

2. Uno Y, Morita T, Luijten M, Beevers C, Hamada S, Itoh S, et al. Micronucleus test in rodent tissues other than liver or erythrocytes: report of the IWGT working group. Mutat Res. 2015;783:19-22. https://doi.org/10.1016/j. mrgentox.2015.03.001.
3. Kirkland D, Uno Y, Luijten M, Beevers C, van Benthem J, Burlinson B, et al. In vivo genotoxicity testing strategies: report from the 7th international workshop on genotoxicity testing (IWGT). Mutat Res. 2019;847:403035.

4. Narumi K, Ashizawa K, Takashima R, Takasawa H, Katayama S, Tsuzuki Y, et al. Development of repeated-dose liver micronucleus assay using adult rats: an investigation of diethylnitrosamine and 2,4-diaminotoluene. Mutat Res. 2010;747(2):234-9. https://doi.org/10.1016/j.mrgentox.2012.05.012.

5. Takayanagi T, Takashima R, Wako Y, Kawasako K, Tanaka Y, Hori H, et al. Repeated dose liver micronucleus assay using clofibrate in young adult rats. Mutat Res. 2015;780-781:117-22. https://doi.org/10.1016/.jmrgentox.2015.01.002.

6. Kastenbaum MA, Bowman KO. Tables for determining the statistical significance of mutation frequencies. Mutat Res. 1979;9(5):527-49. https:// doi.org/10.1016/0027-5107(70)90038-2.

7. Hamada S, Nakajima N, Namiki C, Serikawa T, Hayashi M. The effect of aging on the rat micronucleus assay. Mutagenesis. 2003;18(3):273-5. https://doi. org/10.1093/mutage/18.3.273.

8. Suzuki H, Ikeda N, Kobayashi K, Terashima Y, Shimada Y, Suzuki T, et al. Evaluation of liver and peripheral blood micronucleus assays with 9 chemicals using young rats. A study by the collaborative study Group for the Micronucleus Test (CSGMT)/Japanese environmental mutagen society (JEMS)-mammalian mutagenicity study group (MMS). Mutat Res. 2005;583(2): 133-45. https://doi.org/10.1016/j.mrgentox.2005.03.012.

9. Suzuki H, Takasawa H, Kobayashi K, Terashima Y, Shimada Y, Ogawa I, et al. Evaluation of a liver micronucleus assay with 12 chemicals using young rats (II): a study by the collaborative study Group for the Micronucleus Test/Japanese environmental mutagen society-mammalian mutagenicity study group. Mutagenesis. 2009;24(1):9-16. https://doi.org/10.1093/mutage/gen047.

10. Takasawa H, Suzuki H, Ogawa I, Shimada Y, Kobayashi K, Terashima Y, et al. Evaluation of a liver micronucleus assay in young rats (III): a study using nine hepatotoxicants by the collaborative study Group for the Micronucleus Test (CSGMT)/Japanese environmental mutagen society (JEMS)-mammalian mutagenicity study group (MMS). Mutat Res. 2010;698(1-2):30-7. https://doi. org/10.1016/j.mrgentox.2010.02.009.

11. Takasawa H, Suzuki H, Ogawa I, Shimada Y, Kobayashi K, Terashima Y, et al. Evaluation of a liver micronucleus assay in young rats (IV): a study using a double-dosing/single-sampling method by the collaborative study Group for the Micronucleus Test (CSGMT)/Japanese environmental mutagen society (JEMS)-mammalian mutagenicity study group (MMS). Mutat Res. 2010;698(1-2):24-9. https://doi.org/10.1016/j.mrgentox.2010.02.010.

12. Uno Y, Takasawa H, Miyagawa M, Inoue Y, Murata T, Ogawa M, et al. In vivo-in vitro replicative DNA synthesis (RDS) test using perfused rat livers as an early prediction assay for nongenotoxic hepatocarcinogens: I. Establishment of a standard protocol. Toxicol Lett. 1992;63(2):191-9. https:// doi.org/10.1016/0378-4274(92)90011-8.

13. Asaoka Y, Sakai H, Sasaki J, Goryo M, Yanai T, Masegi T, et al. Changes in the gene expression and enzyme activity of hepatic cytochrome P450 in juvenile Sprague-Dawley rats. J Vet Med Sci. 2010;72(4):471-9. https://doi. org/10.1292/jvms.09-0397.

\section{Publisher's Note}

Springer Nature remains neutral with regard to jurisdictional claims in published maps and institutional affiliations.

\section{Ready to submit your research? Choose BMC and benefit from:}

- fast, convenient online submission

- thorough peer review by experienced researchers in your field

- rapid publication on acceptance

- support for research data, including large and complex data types

- gold Open Access which fosters wider collaboration and increased citations

- maximum visibility for your research: over $100 \mathrm{M}$ website views per year

At BMC, research is always in progress.

Learn more biomedcentral.com/submission 